\title{
Changing trend of neural tube defects in Eastern Turkey
}

\author{
H Güvenc, M Ali Uslu, M Güvenc, U Ozekici, K Kocabay, S Bektaş
}

\begin{abstract}
Study objective-The aim was to study the relationship between birth prevalence of neural tube defect (including anencephaly) in Eastern Turkey before and after the Chernobyl disaster.
\end{abstract}

Design-This was a prospective study of time trends in live births and stillbirths over the years 1985-1990. Medical and sociodemographic data were recorded for the mothers.

Setting-Elazig, Eastern Turkey.

Subjects-There were 5240 live births and stillbirths during the study period, 24 of whom had neural tube defect and of these 20 had anencephaly.

Main results-Of the 5240 newborns, 24 had a neural tube defect, giving a birth prevalence of 4.5 per 1000 total births. Of these, 20 were anencephalic ( $3 \cdot 8$ per 1000$)$. In all, of the 2355 conceptions estimated to have occurred prior to the Chernobyl disaster in May 1986, the birth prevalences of total neural tube defect and anencephaly were the same $(1 \cdot 7$ per 1000$)$. This contrasts with the years following after Chernobyl, when the birth prevalence of total neural tube defect was 6.9 per $1000(5.5$ per 1000 for anencephaly). The differences were statistically significant $(p<0.001)$. These two increased rates reached a peak of 12.4 (for total neural tube defects) and 8.9 (for anencephaly) in 1988. In 1989 the rate of total neural tube defects decreased to 10.0 and that of anencephaly to 8.6 per 1000 . In 1990 the rate of total neural tube defects fell to $5 \cdot 6$ and that of anencephaly fell to $4 \cdot 2$.

Conclusions-The changes in birth prevalence of neural tube defects might be due to the Chernobyl disaster. However, the increases observed occurred mainly in infants conceived well over a year after the Chernobyl disaster, suggesting that other factors may be responsible.

f Epidemiol Community Health 1993; 47: 40-41

Neural tube defects, especially anencephaly, constitute the most common type of malformation of the central nervous system in humans. Their aetiology is probably multifactorial and results from the combined actions of genetic and environmental factors. Although various investigators have reported a birth prevalence of 1.5 to 2.6 per 1000 births for Turkey, ${ }^{1-5}$ a marked increase in total neural tube defects including anencephaly among conceptions occurring after the Chernobyl disaster has been noticed in three recent studies ${ }^{6-8}(20,8 \cdot 9$, and $4 \cdot 4$ per 1000 births, respectively). It is claimed that this might be due to the nuclear wave from Chernobyl affecting the conceptus after May 1986. In the current study we therefore examine new data on the birth prevalence of neural tube defects for Turkey.

\section{Methods}

The study was carried out in Elaziğ, Eastern Turkey. The population of Elazig itself is 200000 but is approximately half a million with the surrounding towns and villages. The data were prospectively obtained by us from the Departments of Paediatrics and Obstetrics and Gynaecology dating from 1985. All livebirths and stillbirths resulting from pregnancies of more than 28 weeks gestation were reviewed from January 1985 to December 1990. Every newborn was examined by a paediatrician within 24 hours of birth and the numbers of total births and newborns with neural tube defects were determined. Additionally, mothers' ages and parity status, histories of present and previous pregnancies for pyrexial illness radiography and medication, consanguinity rate, and socioeconomic status of parents were recorded routinely.

Statistical evaluation were made using the $t$ test and $\chi^{2}$ analysis.

\section{Results}

Total births and births with neural tube defects between 1985 and 1990 are summarised in table I. Of the total of 5240 livebirths and stillbirths, 24 had a neural tube defect, a birth prevalence of 4.5 per 1000 total births. Of these, 20 were anencephalic (birth prevalence 3.8 per 1000 ). In all, of the 2355 conceptions estimated to have occurred prior to the Chernobyl disaster, the birth prevalences of total neural tube defect and anencephaly were the same (1.7 per 1000). This contrasts with the years after Chernobyl, when the birth prevalence of total neural tube defect was 6.9 per 1000 (birth prevalence of anencephaly 5.5 per 1000). The differences were statistically significant $(p<0.001)$. These two increased rates reached a peak of 12.4 (for total neural tube defects) and 6.9 (for anencephaly) in 1988. In 1989 the rate of total neural tube defects decreased to 10.0 and that of anencephaly to 8.6 per 1000 . In 1990 the rate of total neural tube defects fell to $5 \cdot 6$ and that of anencephaly to $4 \cdot 2$.

For the mothers of newborns with neural tube defects and of a randomly selected sample of 50 healthy newborns, several factors including maternal age, parity, consanguinity rate, and 
Table I Birth

prevalences of neural tube defects (NTD) in Elaziğ, Eastern Turkey, 1985 to 1990

\begin{tabular}{|c|c|c|c|c|c|}
\hline \multirow[b]{2}{*}{ Years } & \multirow{2}{*}{$\begin{array}{l}\text { Total number } \\
\text { of births }\end{array}$} & \multicolumn{2}{|c|}{ Total NTD } & \multicolumn{2}{|c|}{ Anencephaly } \\
\hline & & $n$ & rate & $n$ & rate \\
\hline $\begin{array}{l}1985 \\
1986 \\
1987 \\
1988 \\
1989 \\
1990\end{array}$ & $\begin{array}{r}1265 \\
1090 \\
914 \\
562 \\
695 \\
714\end{array}$ & $\begin{array}{l}3 \\
1 \\
2 \\
7 \\
7 \\
4\end{array}$ & $\begin{array}{r}2.3 \\
0.9 \\
2.1 \\
12.4 \\
10.0 \\
5.6\end{array}$ & $\begin{array}{l}3 \\
1 \\
2 \\
5 \\
6 \\
3\end{array}$ & $\begin{array}{l}2 \cdot 3 \\
0.9 \\
2 \cdot 1 \\
8.9 \\
8.6 \\
4 \cdot 2\end{array}$ \\
\hline
\end{tabular}

*per 1000 total births

socioeconomic status were unimportant (table II) and histories of present and previous pregnancies were similar.

\section{Discussion}

Our previous study ${ }^{5}$ in Elaziğ, Eastern Turkey, showed that the yearly birth prevalence of anencephaly between 1978 and 1987 was 1.5 per 1000 total births, and the corresponding rate was $2 \cdot 1$ per 1000 in 1987 just after the Chernobyl disaster. Although there was a marked increase in total neural tube defects including anencephaly (20 and 8.9 per 1000 in the two recent studies ${ }^{67}$ ) in Western Turkey during 1987, in the same period our data from Eastern Turkey, which is approximately the same distance from Chernobyl, showed no significant increase in the incidence of anencephaly. This finding was in agreement with that of EUROCAT Working Group. ${ }^{9}$ However, during the last three years in our region, higher birth prevalences in total neural tube defects and anencephaly were found, with a peak of 12.4 and 8.9 per 1000 in 1988 , respectively. In contrast, an increased birth prevalence just after the Chernobyl disaster in the studies of Akar et al and

Table II Several factors in the mothers of newborns with neural tube defects (NTD) and of randomised healthy newborns.

\begin{tabular}{llll}
\hline & $\begin{array}{c}\text { NTD newborns } \\
(n=24)\end{array}$ & $\begin{array}{c}\text { Healthy newborns } \\
(n=50)\end{array}$ & $p$ \\
\hline Maternal age (years), mean (SD) & $27 \cdot 8(5 \cdot 6)$ & $25 \cdot 6(5 \cdot 2)$ & $>0.05^{1}$ \\
Parity, mean (SD) & $5.6(2 \cdot 3)$ & $5 \cdot 3(2 \cdot 1)$ & $>0.05^{1}$ \\
Consanguinity rate & $26 \%$ & $21 \%$ & $>0.05^{2}$ \\
Low socioeconomic status & $79 \%$ & $72 \%$ & $>0.05^{2}$ \\
\hline${ }^{1} t$ test & & & \\
${ }^{2} \chi^{2}$ analysis & & &
\end{tabular}

Cağiayan $e t a l^{7}$ then declined over the following 6-12 months and finally achieved the preChernobyl level. ${ }^{10}$ Additionally, the fact that post-Chernobyl total neural tube defects and anencephaly rates increased to levels of 6.9 and $5 \cdot 5$ per 1000 in comparison to pre-Chernobyl levels of 1.7 per 1000 in our study needs explanation.

According to Akar et al, ${ }^{6}$ Çağlayan et $a l,{ }^{7}$ and Mocan $e t a^{8}$ the dramatic change in birth prevalence may be associated with the Chernobyl disaster of May 1986. However, the cause of many congenital malformations of the central nervous system remains obscure, and the fact that in our study the increase occurred mainly among infants conceived well over a year after the Chernobyl disaster suggests that other factors may be responsible. Therefore, new epidemiological and biochemical data from both Turkey and other European countries are urgently needed in order to explain the changing incidence.

1 Say BE, Tuncbilek E, Balci S, et al. Incidence of congenital malformations in a sample of the Turkish population. Hum Hered 1973; 3: 230-2.

2 Ilter O, Atasu T, Aksu MF. Central nervous system abnormalities in Istanbul. Med Bull Istanbul 1978; 11: abnorm.

3 Buckley WR, Erten O. The epidemiology of anencephaly and spina bifida in Izmir, Turkey in the light of recent and spina bifida in Izmir, Turkey in the light of recent aetiologic

4 Cavdar AO, Arcasoy A, Babacan E, et al. Zinc levels of serum, plasma, erythrocytes and hair in Turkish women with anencephalic babies. In: Prasad AS, Cavdar AP Brewer J, Agget P, eds. Zinc deficiency in human subjects. New York: Alan R. Liss, 1983: 99-106.

5 Güvenc H, Uslu MA, Okten A, et al. Incidence of anencephaly in Elaziö, Eastern Turkey. Paediatr Perinat Epidemiol 1989; 3: 230-2.

6 Akar N, Cavdar AO, Arcasoy A. High incidence of neura tube defects in Bursa, Turkey. Paediatr Perinat Epidemio 1988; 2: 89-92.

7 Chăglayan S, Kayhan B, Menteşoğlu S, Akşit S. Changing incidence of neural tube defects in Aegean Turkey. Paediatr Perinat Epidemiol 1989; 3: 65-8.

8 Mocan H, Bozkaya H, Mocan MZ, et al. Changing incidence of anencephaly in the eastern Black Sea region of Turkey of anencephaly in the eastern Black Sea region of Turkey and Chernobyl. Paediatr Perinat Epidemiol 1990; 4: 264-8. EUROCAT Working Group. Preliminary evaluation of the impact of the Chernobyl radiological contamination on the frequency of central nervous system malformations in 18 regions

10 Akar N, Ata Y, Aytekin AF. Neural tube defects and Chernobyl? Paediatr Perinat Epidemiol 1989; 3: 102-3. 